\title{
Constraints of Electricity Mini Off-Grid Systems Diffusion for Entrepreneurship in Rural Areas of Zambia
}

\author{
William Mtonga ${ }^{a}$, Engineer Dr. Kasongo Richard Mwale ${ }^{\mathrm{b}}$, Professor Biemba Maliti ${ }^{\mathrm{c}}$ \\ a mtongawilliam@gmail.com, Lusaka 10101, Zambia \\ bengkasongo@gmail.com, Lusaka, 10101, Zambia \\ ‘malitibm@gmail.com, Kitwe, 10101, Zambia
}

Paper Reference ID: 100761520211914, Publication Date: 21 May 2021, ISSN: 2708-3578, Vol. 76

\begin{abstract}
The low electrification rate of about $52 \%$ and an estimated $28 \%$ for Africa and Zambia respectively is of concern. There is now a common consensus that renewable energy electricity mini off-grid systems (or simply mini-grids) have a great role to play to reverse the trend especially in remote rural areas that are located farthest from respective national main grids in order to achieve the United Nations Sustainable Development Goal Number 7 which specifically challenges for universal access to sustainable energy by 2030 . This study sought to establish the constraints of diffusion for mini-grids intended for entrepreneurial purposes in rural areas of Zambia. The embedded research design; where quantitative data was collected and analysed then followed by collection and analysis of qualitative data was employed for this study. The exponential discriminative snowball sampling technique was used to collect data from a sample of 37 respondents. Likert scales were used to analyse quantitative data in combination with the coefficient of variance and the degree of consensus, while thematic analysis was used to analyse qualitative data. The study established the following constraints of diffusion of mini-grids for entrepreneurial purposes in rural areas of Zambia: high poverty levels, low population density, low profitability of the mini-grids business, substitute products provide cheap energy sources, fear of the main grid encroachment, high upfront capital expenditure required for setting up the mini-grids business, local taxes, seasonality of business, lack of access to capital finance and limited business ideas, government policy and regulations, ignorance about existence of mini-grids and their benefits, lack of incentives such as capital subsidies, business environment varies depending on specific locations and challenging physical geographical conditions. The study conclusively found that; consumer sensitization, the marketing concept and referral marketing are the most effective strategies for promoting diffusion for mini-grids in rural areas of Zambia, supported by the declining costs for renewable energy technologies on the market. The study recommended that sensitization should be intensified since communities respond positively whenever enlightened about the existence of mini grids and their benefits for entrepreneurial purposes. Further, the catchment area for customers deriving benefit from a particular mini-grid should be wide enough by installing mini-grids well far apart to allow attainment of sales critical mass in view of low population density and low profitability in rural areas of Zambia.
\end{abstract}

Key words: Constraints; Diffusion; Electricity; Entrepreneurship; Mini-grids; Renewable Energy; Zambia

This article is an extract of the thesis submitted by William Mtonga to the School of Postgraduate Studies of the University of Lusaka in fulfilment of the requirement for the award of the Doctor of Philosophy Degree in Entrepreneurship. The Research was supervised by the co-authors; Engineer Dr. Kasongo Richard Mwale and Professor Biemba Maliti. 
Electrification of rural areas is achieved either through; grid extension, standalone solar systems or electricity mini off-grid systems. The use of electricity mini off-grid systems or simply referred to as mini-grids for rural electrification to spur entrepreneurship is on the rise as it allows natives to engage in productive uses of the electricity to improve their quality of life in addition to household energy uses such as basic lighting. The entrepreneurial activities undertaken using mini-grids include: food processing such as - operating; hammer mills for grinding maize to produce mealie-meal or maize meal used for cooking the staple food nshima, oil press for extracting cooking oil from sunflower seeds and groundnuts, freezers for making ice cubes for fish preservation and other perishable food stuffs, freeze-it machines for making edible ice blocks for cooling the human body, refrigeration units for butchery and bottle stores; engaging in body care activity by operating hair saloons using tools such as barbing machines and hair dryers and also engaging in powering of tools for welding, irrigation pumping and carpentry workshops among others.

Africa has the lowest electrification rate at $52 \%$ with Zambia's electrification rate estimated at $28 \%$ and there is a common consensus now that mini-grids systems have a great role to play to reverse the trend in order to meet the United Nations Sustainable Development Goal Number 7 (UNSDG 7) which calls for universal access to sustainable energy by 2030 with specific targets (Renewables in Africa, 2018; Get.invest, 2019; United Nations). Also IRENA (2018) points out that concerted action is required across multiple elements of an enabling environment for scaling up off-grid solutions in order to accelerate progress towards achieving the UNSDG 7 goal on universal electricity access.

Zambia is confronted with an increasing energy demand, resulting from demographic and socioeconomic factors, at an average of 6 percent or 150 - 200 megawatts (MW) per annum according to the National Energy Policy (2019, p.7). The main electricity grid transmission and distribution infrastructure in Zambia is concentrated along the line of rail (urban areas) with grid extension to some peri-urban areas, but excludes most rural areas thereby adversely affecting entrepreneurial activity in rural areas. The high cost associated with extending electricity supply to rural areas and a general lack of affordability for electricity by consumers in rural areas are among challenges affecting extending grid connection of electricity to rural areas, thereby causing the electricity supply gap between the urban and rural areas. The coming of the electricity mini-grids technology serves a variety of customers who include; private households for own use to small and large commercial customers for entrepreneurial purposes in rural areas. The said electricity mini-grids are commonly fuelled by hydro or solar renewable energy sources as fossil fuel based mini-grids are gradually being phased out in order to reduce greenhouse gas emissions to limit climate warming.

The author noted that for the period 2013 to 2019; the diffusion (wide spreading) or adoption rate of electricity mini off-grid systems was slow despite the technology being available and known to be cost effective to provide timely solution for meeting the electricity requirements in rural areas of Zambia. Hence, this study sought to establish the constraints of diffusion for mini-grids intended for entrepreneurial purposes in rural areas of Zambia. 


\section{0}

William Mtonga / International Journal of Research Publications (IJRP.ORG)

The operational terms used in this article are as defined in table 1 below.

Table 1: Terms and definitions used in this article

$\begin{array}{ll}\text { Term } & \text { Definition } \\ \text { Constraints } & \text { Something that limits someone's freedom of action (Collins English School Dictionary, 2018) } \\ \text { Critical mass of sales } & \begin{array}{l}\text { A point where sales cover fixed costs for a company to operate self-sufficiently and sustainably } \\ \text { (Johnson et al, 2011). }\end{array} \\ \text { Diffusion } & \begin{array}{l}\text { Diffusion is the process in which an innovation is communicated through certain channels over time } \\ \text { among the members of a social system (Rogers, 2003). In this study, diffusion is also used to } \\ \text { describe the act of spreading or promulgating an innovation widely to cover wide spread population. }\end{array} \\ \text { Electricity mini off-grid } & \begin{array}{l}\text { The Energypedia defines a mini-grid also sometimes referred to as a "micro grid or isolated grid" as } \\ \text { a set of electricity generators and possibly energy storage systems interconnected to a distribution } \\ \text { network that supplies electricity to a localized group of customers. The mini grid policy toolkit } \\ \text { agrees with energypedia that mini-grids involve small-scale electricity generation (10 kW to } \\ \text { 10MW) which serve a limited number of consumers via a distribution grid that can operate in } \\ \text { isolation from national electricity transmission network. }\end{array}\end{array}$

Entrepreneurship

Entrepreneurship is the control and deployment of resources to create an innovative economic organization (or network of organizations) for the purpose of gain or growth under conditions of risk and uncertainty (Dollinger, 2008, p.9)

Rural Area

(a) Any area which is not an area declared or deemed to have been declared a city or municipality under Local Government Act; Or Cap. 81, (b) such other area as the Minister may, by statutory order and in consultation with the Minister responsible for local government, declare a rural area (Rural Electrification Act no. 20 of 2003)

Supply of electricity

Delivery of electric power using distribution lines to consumers through a supplier-consumer interface point.

Electrical power transmission involves the bulk movement of electrical energy from a generating site, such as a power station or power plant, to an electrical substation where voltage is transformed and distributed to consumers or other substations (Grigsby, 2006; James, 2020)

\subsection{Methodology}

The philosophical view or world view or paradigm forming the foundation perspective carrying a set of assumptions that guided this research process was pragmatism. It was chosen because it applies to mixed methods research whereby inquirers draw liberally from both quantitative and qualitative assumptions when they engage in their research focusing attention on the research problem and use pluralistic approaches to derive knowledge about the problem. Pragmatism is a philosophical underpinning for mixed methods studies (Creswell, 2009). For the mixed method approach, the embedded design strategy was chosen for this study, where the researcher collects and analyzes quantitative and qualitative data sequentially to build from one phase of the study to another by following up a quantitative study qualitatively in order to obtain detailed information (Creswell and Clark, 2011).

The target population comprised Operators of electricity mini-grid systems in Zambia, Industry Experts who among them were Regulators dwelling in various parts of Zambia. The sampling frame could not out rightly 
be constituted or identified because the players involved in the electricity mini-grids in Zambia are few and diverse making it hard to reach them unless on referral basis. Hence, the non-probability (non-random) sampling technique called Snowball sampling also known as chain-referral sampling was used in this study since the sample had traits or characteristics that are rare and difficult to find. The study sample comprised 37 respondents numerically broken down as six (6) Operators of electricity mini-grid systems and 31 Industry experts who among them were 13 Regulators.

Data collection was achieved by using survey questionnaires with mostly closed ended questions for quantitative data, while qualitative data was collected through interviewing key informants, focus groups and field notes taken during site visits. Document reviews augmented data collected for both quantitative and qualitative methods.

Quantitative data was analysed using the Likert scale (Likert, 1932) followed by the use of the coefficient of variation (CV) to ascertain level of dispersion of actual values around the mean (Vaz et al, 2017). Qualitative data was analysed using thematic analysis which is essentially a method for identifying and analysing patterns in qualitative data (Braun and Clarke, 2006).

To enable the author obtain an assessment of the questions' validity and reliability of the data that would be collected using the study questionnaires prior to using it for collecting data for the main study, a pilot study was carried out as recommended by Saunders et al (2009, p.394). Further, the internal consistency reliability was established using Cronbach's Alpha reliability coefficient. The overall reliability of Cronbach's Alpha coefficient of 0.792 indicated a high level of internal consistency that was acceptable to proceed with the scale used for this study (Bonett and Wright, 2014; Laerd Statistics, n.d.; Gottems et al, 2018).

\subsection{Results and Discussion}

The main constraints of diffusion of electricity mini off-grid systems for entrepreneurial purposes in remote rural areas of Zambia that relate to siting where to install the mini-grid could be dealt with at prefeasibility stage based on a site selection criteria like one developed by Murunga et al (2014). Site related constraints include; willingness and ability of rural dwellers to pay for electricity services, Low population density, Low profitability, substitute products such as fire wood and petroleum products like Kerosene and Diesel and fear of main grid encroachment on earmarked mini-grid territory for exclusive rights of supply. In addition, the following constraints were learnt through interviews with mini-grids operators and industry experts:

i) High upfront capital expenditure costs: these relate to costs for; surveying potential areas for site identification and selection, obtaining the necessary approvals from various government agencies and traditional leaders (where applicable for sites that are situated on customary land), technical advisory services such as choice of appropriate technology to meet identified customer needs, procurement of the actual technology equipment to be installed and actual specialized labour for carrying out installation of the generation plant and distribution network .

ii) Taxes that apply to procurement of the mini-grid technology equipment to be installed such as import VAT and customs clearance tax. After installation, there are local taxes such as excise duty paid on produced electricity payable to Zambia Revenue Authority. Excise duty was cited as the tax that does not incentivize the mushrooming electricity mini-grids business and options such as tax holiday or waiver of excise duty may be considered by the government to enable the mini-grid business get established. 
iii) Business seasonality due to fiscal cycles that occur in rural communities. There is a period when rural communities sell harvested farm produce and they tend to have enough money with which they are willing to pay for commodities such as electricity. As their money runs low, spending reduces as expenditure begins to be prioritized by avoiding things they can do without such as electricity in preference for substitute products such as petroleum based fuels and firewood. The fluctuations in the spending patterns introduce a distinct feature characterized by peaks and troughs in electricity sales and thus cause business seasonality for rural areas which happens to be a constraint to diffusion of mini-grids. In order to address the "off business season" or troughs in electricity sales, mini-grids developers train and support their customers (those running entrepreneurial activities based on electricity supplied from the mini-grid) to ensure they sustain their enterprises so as not to close since the success of customers' business entails success for the mini-grid operator as well. The training provided involves cash management and business diversification that ensures the customer remains connected to the electricity mini-grid.

iv) Low population density avails limited customer base not only for the mini-grid operator, but also for those engaged in entrepreneurial activities that productively use the electricity supplied from the mini-grid. Low population density causes a challenge to attain a critical mass of sales that cover fixed costs for an enterprise to operate self-sufficiently and sustainably due to low demand for the products or services. Critical mass is reached when the sales for a product or service becomes self-sustaining as there is retention of existing customers, while new customers come on board adopting the new innovation and result in profitability over time (Johnson et al, 2011). For the mini-grid business, achieving a critical mass of sales requires the catchment area for communities deriving benefit from a particular mini-grid (customers) to be wide enough. This implies that electricity mini-grids should be sited far away from each other so that there can only be a single electricity mini-grid within an estimated radius. That is how low population density affects diffusion of electricity mini off-grids for entrepreneurial purposes in rural areas of Zambia.

v) Access to Finance and Limited business ideas: coincidentally, communities in the rural areas which are targeted for installation of electricity mini-grids experience high poverty levels rendering them limited access to finance or capital to acquire efficient appliances needed to engage in income generation activities and low capacity to pay for electricity services. Further, people in rural communities tend to have limited business ideas. For example; if one starts a bottle store business and appears successful, community members would want the same type of business instead of starting up own ideas that could cause diversification of services offered to the community.

vi) Government policy to promote installation and operation of mini-grids is not clear and that contributes to the business risk. For instance, the security of tenure for mini-grids in case of grid arrival or encroachment remains vague despite attempts to cover it under regulations that were undergoing development at the time of the survey.

vii) Ignorance of people about mini-grids: although mini off-grids are generally targeted for the rural areas, the rural communities are ignorant about the existence of mini grids and their benefits. The survey established that the extent of consumers' awareness about electricity minigrids as an innovation in rural areas is low because spreading of information by Operators and other Stakeholders to sensitize target consumers about their existence and benefits was low. 
viii) Lack of support in form of incentives in Zambia: governments assist businesses in a particular industry as a control measure to maintain prices for their goods or services competitively affordable aiming at improving the availability of goods and services for the society. In this case, provision of smart subsidies to eligible mini-grid developers in form of capital subsidies, which relate to capital expenditure materials for the generation and distribution network could have a direct impact on the final pricing or the tariff charged for the electricity supplied from the mini-grid. Access to cheap source of local financing for developing mini-grids could have a similar effect of making electricity supplied from mini-grid affordable.

\subsection{Conclusion and recommendation}

Electricity mini-grids could help member states of the United Nations to attain energy access goals as provided by the Sustainable Development Goals (SDGs) specifically goal number 7 on ensuring access to affordable, reliable, sustainable and modern energy for all by 2030. The scaling up of electricity mini-grids diffusion requires concerted efforts from all stakeholders such as mini-grid operators, government and the general public. This study revealed that consumer sensitization, the marketing concept and referral marketing are the most effective strategies for promoting diffusion for mini-grids in rural areas of Zambia. The declining costs for renewable energy technologies on the global market could further promote diffusion of mini-grids in rural areas of Zambia for entrepreneurial activities.

In view of the highlighted constraints of diffusion of mini-grids, the author recommends:

i) Intensifying the spreading of information about the existence of electricity mini grids and their benefits by Operators and Stakeholders to target rural area communities. This is because findings of the study showed that communities in rural areas respond positively once enlightened about existence of electricity mini grids and their benefits for entrepreneurial purposes;

ii) In order to mitigate the challenge of attaining a critical mass of sales due to low population density in rural areas of Zambia for both the mini-grid operator and enterprises engaged in productive use of the electricity supplied from the mini-grid, the catchment area for customers deriving benefit from a particular mini-grid should be wide enough by siting mini-grids far away from each other. Otherwise, establishing mini-grids near each other could cause them to be unsuccessful in the event that the critical mass is not attained;

iii) The Zambian government should consider awarding tax holidays on payment of excise duty for electricity produced from mini-grids specifically to incentivize the mushrooming electricity mini-grids business as it holds a potentially huge promise to alleviate poverty among rural communities engaged in entrepreneurial activities as the benefits spill over to their customers who improve their quality of life through access to various amenities;

iv) Provision of smart subsidies to eligible mini-grid developers in form of capital subsidies that relate to capital expenditure materials needed for the generation plant and distribution network in order to keep tariffs charged for the electricity supplied from the mini-grid affordably low for the rural communities; and

v) The Zambian government through the Ministry of Energy should consider hastening the finalization and enacting of the regulations for renewable energy mini-grids in order to encourage their diffusion. 


\section{References}

Renewables in Africa, 2018, article on how does a green mini-grid work? Available on: https://www.energyjobline.com/article/how-doesa-green-mini-grid-work/, Accessed on: 17 August 2020

Get.invest market insights, 2019, Zambia: Solar PV and Hydro Mini-Grids Model Business Case: Hydro Mini-Grid for Rural Electrification, Available on: www.get-invest.eu, Accessed on: 19 November 2020

United Nations, United Nations Sustainable Development Goals (UNSDGs), Available on: https://sdgs.un.org/goals, Accessed on: 31 March 2019

International Renewable Energy Agency (IRENA), 2018, Report on Policies and Regulations for Renewable Energy Mini-grids Publication

National Energy Policy, 2019, Ministry of Energy, Republic of Zambia

Collins English School Dictionary, 2018, $6^{\text {th }}$ Edition, HarperCollins Publishers, Glasgow, United Kingdom

Gerry Johnson, Richard Whittington and Kevan Scholes, 2011, Exploring Strategy, $9^{\text {th }}$ Edition, Financial Times Prentice Hall - Pearson Education Limited, England

Everett M. Rogers, 2003, Diffusion of Innovations, $5^{\text {th }}$ Edition, Free Press a Division of Simon \& Schuster, Inc., New York, USA

Leonard L. Grigsby, 2006, Electric Power Generation, Transmission, and Distribution, Electric Power Engineering Handbook, $2^{\text {nd }}$ Edition, Taylor \& Francis Group, LLC, Florida, United States

Energypedia, 2019, Mini grids definition and overview, available online: 〈https://energypedia.info/wiki/Mini_Grids>, Accessed on: 1 April 2019

Marc J. Dollinger, 2008, Entrepreneurship: strategies and resources, $4^{\text {th }}$ Edition, Marsh Publications LLC, Lombard, Illinois USA

Rural Electrification Act no. 20 of 2003, of the laws of the Republic of Zambia

Luke James, 2020, Electrical Power: Basics of an electrical power transmission system, online publication, available: https://www.powerand-beyond.com/basics-of-an-electrical-power-transmission-system-a-919739/, Accessed on: 27 August 2020

John W. Creswell, 2009, Research Design - Qualitative, Quantitative and Mixed Methods Approaches, $3^{\text {rd }}$ Edition, SAGE Publications, Inc., Thousand Oaks, California, USA

Creswell and Plano Clark, 2011, Designing and conducting mixed methods research, Thousand Oaks, CA: Sage Publications, Inc.

Rensis Likert, 1932, a technique for the measurement of attitudes, Archives of Psychology, volume 22, New York, USA.

Marcos André Braz Vaz, Paulo Santana Pacheco, Enio Júnior Seidel and Angela Pellegrin Ansuj, 2017, Classification of the coefficient of variation to variables in beef cattle experiments, Ciência Rural, Brazil, Available online: https://www.scielo.br/scielo.php?script=sci_arttext\&pid=S0103-84782017001100651\&lng=en\&tlng=en, Accessed on: 1 May 2020.

Virginia Braun and Victoria Clarke, 2006, using thematic analysis in psychology, available: https://core.ac.uk/download/pdf/1347976.pdf, Accessed on: 30 April 2020.

Mark Saunders, Philip Lewis and Adrian Thornhill, 2009, Research Methods for business students, $5^{\text {th }}$ Edition, Pearson Education Limited, Essex, England

Douglas G. Bonett and Thomas A. Wright, 2014, Journal of Organizational Behavior, Published online in Wiley Online Library, DOI: 10.1002/job.1960, Accessed on: 28 March 2021

Laerd Statistics, n.d., Cronbach's Alpha $(\alpha)$ using SPSS Statistics, Available: https://statistics.laerd.com/spss-tutorials/cronbachs-alphausing-spss-statistics.php\#interpreting, Accessed on: 28 March 2021

Leila Bernarda Donato Gottems, Elisabete Mesquita Peres De Carvalho, Dirce Guilhem, and Maria Raquel Gomes Maia Pires, 2018, Good practices in normal childbirth: reliability analysis of an instrument by Cronbach's Alpha1, Rev. Latino-Am. Enfermagem, Available: http://dx.doi.org/10.1590/1518-8345.2234.3000, Accessed on: 28 March 2021

Jacinta Murunga, Henry Gichungi, Colleta Koech, Hannington Gochi, 2014, where shall we put it? Solar mini-grid site selection handbook, Published by the German Climate and Technology Initiative Promotion of Solar-Hybrid Mini-Grids in Kenya, available on: https://energypedia.info/images/4/48/GIZ2014-en-where-shall-we-put-it-kenya.pdf, Accessed on: 18 November 2020 